\title{
Cross Cultural Negotiations for Greater MNC Competitiveness
}

\author{
Yezdi H. Godiwalla ${ }^{1} \&$ James W. Bronson ${ }^{2}$ \\ ${ }^{1,2}$ Management Department, College of Business and Economics, University of Wisconsin-Whitewater, USA \\ Correspondence: Yezdi H. Godiwalla, Management Department, University of Wisconsin-Whitewater, Whitewater, \\ Wisconsin 53190-1790, USA
}

Received: July 24, 2015

Accepted: August 7, $2015 \quad$ Available online: August 12, 2015

doi:10.11114/aef.v2i4.1034

URL: http://dx.doi.org/10.11114/aef.v2i4.1034

\begin{abstract}
Good negotiation is not a compelling interaction to unilaterally achieve one's goals even at the expense of fairness to the other party. It is a careful and conscientious and methodical approach for true understanding and empathy, responding and appealing to the other party's sensitive and important needs, expectations and anxieties. It is particularly appealing to the negotiator's good sense of what is balanced, equitable and meaningful such that it is simultaneously to advantageous and relevant in the circumstances to both parties. There can be the adversarial atmosphere among the two (or more) parties that are involved in negotiation so that it requires a systematic approach of blending the following issues: appropriate and viable negotiation strategy, making culturally correct approaches and appeals to the other parties, projecting culturally correct personal values and organizational goals and images, gently generating, in the correct sequence, the proper issues and questions, and effectively offering meaningful and helpful suggestions, modifications and the needed adjustments for the other party. Good negotiation is done by keeping in his (or her) mind the context of the situation and the other party's overall personal expectations and organizational needs, particularly his organization's economic, social, cultural, infrastructural, and emotional needs and conditions.
\end{abstract}

Keywords: cross cultural negotiations, negotiations for MNC competitiveness, international negotiations

\section{Introduction}

\subsection{Nature of Negotiation Process: Its Need and Importance}

Negotiations are important and often stressful, if not difficult and complex. We negotiate in many ways in our everyday lives. Even within the same culture, even within the same family, office, playground, or club, we negotiate. As we communicate, we feel our limits of influence, and, we often want to increase the boundaries of influence with others around us. Thus, children negotiate with their parents, and, aged parents negotiate with their adult children upon whom they may be dependent. Negotiations within one culture are difficult and stressful. Negotiations across two or more cultures are even more complicated because of cultural differences.

When we negotiate within the same family, company, club, national and regional cultures, we know how to communicate because we know how our messages will be received. And, given our assessment of the situation and the interpersonal relationship and confidence we enjoy with the other person(s), we can estimate how the person(s) would respond to our requests.

\subsection{Definition of Negotiation}

To define, negotiation is the process of discussion (among two or more parties who have similar yet conflicting interests) as the parties interact to achieve their own interests and a mutually acceptable deal, settlement or agreement (Fells, Rogers Prouse and Ott, 2015; Moran and Stripp, 1991). Further, Fells et al (2015) argue the need of an effective negotiation approach, as they state:

"The analysis suggests a pragmatic approach to negotiation, whereby information is not withheld, but neither is it freely given. Solutions emerge from discussion of priorities and commonalities rather than through more formal creative processes. The underlying script of negotiation appears to draw more on competitive than overtly collaborative tactics, suggesting that business negotiators are cautious co-operators."

The negotiation process is a goal oriented activity that is aimed to achieve a satisfactory, mutually beneficial 
agreement or deal. Negotiations take place for many different purposes: sales, international joint ventures, out sources and purchasing supplies and components, managerial, technical and financial cooperation, purchasing assets or companies, governmental license and other legal negotiations, marketing and distribution agreements, labor and other business agreements (Peleckis, 2014). These agreements at first appear elusive because of the conflicting nature of interests as they can often be perceived by the two (or more) parties.

Business transactions are increasingly moving in the international arena, and, in turn, this issue places even greater challenges upon the US or other western negotiators to negotiate with other parties from other cultures. There are a lot of differences in the preferred approaches towards negotiation in different cultures, and, this places the need for a more perceptive, skilled, better prepared negotiator as he straddles across the many cultural divides.

\section{Effective Negotiation: Attributes and Trust}

\subsection{Negotiation Process Attributes}

Effective negotiation is not coercive or harsh interaction to achieve compliance. On the contrary, effective negotiation is a skilled approach to appeal to the other party's sense of what is worthwhile and is also in his (or, her; subsequently "his" explicitly means "his" or "her") interest. Effective negotiation is done by keeping in mind the context of the situation and the other party's needs and mental and emotional make up. Because of the often adversarial situation among the two or more parties, negotiation requires a systematic approach of blending: (a) correct negotiation strategy, (b) making correct appeals to the other parties, (c) projecting correct personal values and organizational goals and images, (d) raising correct issues and questions and (e) timely offering of mutually beneficial recommendations and concessions.

Negotiation requires understanding of the other parties' needs and views. It is enhanced when there is empathy, sincerity and genuine concern for each other's interests (even if these interests are at variance). Negotiation requires patience and to be able to judge the pace of the other parties' preferred levels of pace and intensity of discussion, whether intensely involved in details, or, less detailed focused and more human-to-human focused.

\subsection{Trust is Important}

In many cultures trust is a prerequisite to discussion of business content. In some Middle East cultures the host would not talk business for the first two or three days. During that period he feels out if he can trust the visitor (or negotiator); this is done through social activities. If he feels that he can trust the visitor, then on the third or the fourth day he starts business talks. Otherwise, the visit is concluded, and the guest returns empty handed. A good point to remember is that we must first be able to properly interact at person-to-person levels before we can start meaningful discussions.

\subsection{Effective Negotiator's Attributes and Practices}

An effective negotiator must: (a) have a complete grasp of the details, (b) have a fuller understanding and empathy of the other parties' emotional, mental, economic state, (c) know their appeals (what would make them want to agree to a mutually acceptable settlement or agreement), (d) know what concessions he should make and at what stage(s) in the negotiation process, (e) know what concessions he probably can get from the other parties (and at which stages these concessions probably will be ripe for picking), (f) be intelligent, hardworking and thorough, (g) be creative and flexible, (h) be a very good, relaxed, comfortable communicator, (i) know the laws of the countries involved, (j) understand the culture(s) of the other parties.

\section{The Cross Cultural Negotiation Process}

International, cross cultural negotiation takes place across the boundaries of two or more countries. The crossing of boundaries involves: differences and changes in different values, languages, cultures, laws, physical business conditions and logistics, ways of thinking and communicating, priority system, problems, opportunities, and the ways by which people seek agreement on an issue of conflict. More often a major problem that is felt by the parties is that the different legal, political and control systems make it even more difficult to obtain the achievement of a deal, settlement, or satisfactory solution. Because of these differences the negotiation process is more complicated, and each party has to be mindful of the other parties' constraints due to their respective influence.

\subsection{Governments and Negotiations}

The bilateral governmental and political relationships between the two countries can be another critical factor in negotiations. Changes in governments can drastically change governmental policy and regulations, and, these can undo much earlier negotiations. For example, the former Soviet Union's invasions of Afghanistan, the Soviet Union's disintegration, the fall of the Shah of Iran, or Iraq's invasion of Kuwait are examples of governmental decisions and actions that have implications to the U.S. businessman. These unpredictable events can upset years of efforts to reach a deal. Negotiations are needed here too, at the governmental levels. 
Natural or other calamities (e.g., earthquake in Mexico, floods in Bangladesh, famines in certain parts of Africa, political uprisings in Fiji or Indonesia or Russia), changes in format of government (e.g., overthrow of democracy and establishment of martial rule in Pakistan), continuous unsettled times in the Middle East, and other terrorist and disruptive events are a source of concern to an international negotiator who is attempting to make a deal in another country. These severe situations also call for the best of an international communicator and negotiator.

\subsection{Negotiator's Issues}

Each negotiator has his own inveterate views and values; and his inflexibility can impede his effectiveness. Yet he must transcend his limitations. He must exert himself to better understand and respond to the different decision-making matrix and style. He can steadfastly stick to his own principles, values and culture. What is needed is that each negotiator should create a feeling of goodwill by understanding the other negotiator's cultural, organizational and political realities as they affect the negotiation process. Dramatic changes and events, examples of which are cited in the foregoing, have profound impacts on a negotiation process.

\subsection{Conclusions}

The burden to absorb these impacts and to act with wisdom, maturity and equanimity are the integral roles of a seasoned negotiator. He has to exercise: (a) restraint, even in the most trying and volatile situations, (b) cool, level headed approach even in the face of strenuous and protracted negotiations, (c) willingness to understand and accommodate the other party's views, difficulties and situations, (d) re-orient the negotiation approach to make the other party's negotiation process more comfortable, and (e) tenacity of purpose even when no conclusion appears in sight nor hope on the horizon.

\section{The International Negotiator: His Life and Times}

The international negotiator is an international traveler who has to do his work in the face of a variety of different situations, problems, conditions of living and work, and challenges. All of these are different from those he would encounter in his own country.

He has to practice considerable and fluent cultural sensitivity and behavioral flexibility and focus on quick and easy adaptation and social fluency as he interacts with his organizational colleagues and non-work people. He has to represent his organization and his home country with integrity, fairness, dignity and grace because he represents them and he is regarded as their ambassador. He has to frequently travel and endure its rigor. He is periodically changing the focus of country scenes, from one country to another country, as he changes his attention to different countries' specific negotiation content, issues and problems. In doing so, he has to continually adapt, continually concentrate on different negotiations content, and modify his negotiations strategies.

\subsection{The Unpredictable Nature of Negotiation Pace and Process}

The length of negotiations can be unpredictable, as a seemingly simple negotiation turns into a complex one, an apparent straightforward and logical process turns into a knotty and difficult negotiation problem, and other unpredictable negotiation situations arise. One may remark that what might have been a few days negotiation may eventually be prolonged into a long, seemingly unending month-long negotiation process, each day of which is arduous and patience challenging.

An international negotiator may have a series of many negotiations in many different countries; and, if even one deal takes much more time, he could be on the road for two months before he can be expected home. And he is expected to do all this without showing jet lag, travel fatigue, or disorientation, as he tries to adjust from one negotiation situation to the next as he weaves his path through a series of myriad negotiation problems. He must appear fresh, alert, attentive, sensitive, courteous, polite, responsive, and understanding - all these he must show even though his nerves may be raw and he may long to relax in his own home. He must synchronize his pace, approach and content of negotiation to those of his host. He must adapt to suit to the host country's preferred style of negotiation. He cannot show any awkwardness, ineptness, insensitivity, personal discomfort, hostility, inertia, exasperation, boredom, futility, bad taste, or lack of concern as he projects the images of himself, his company, and his home country during these negotiations.

\subsection{MNC's HQ Must Empower the Negotiator}

The MNC headquarters must significantly empower the negotiator. His superiors must provide him with wide and implicit goals and powers to arrive at good deals or agreements. And yet he may sometimes feel that he has to communicate with his headquarters to seek more information or further changes, concessions and approval in order to progress with the next phase of the negotiation process.

The challenges that an international negotiator faces are many and they are demanding. He feels lonely as he walks the global negotiator's path, for he has no nearby headquarters colleagues to ask for advice, nor an arm's length 
headquarters superior to confer with, nor a nearby headquarters building technical specialist to rely on, nor a factory in a nearby suburb to accommodate an earlier delivery date, nor a telephone call or a hallway-away cost accountant to give precise costs for a modified product. Nay, he does not have any of the collective support that a domestic negotiator usually enjoys.

He walks alone as he struggles to strike a deal in the face of global competition. He has to face his headquarters superiors upon his return to his company and justify his concessions and his deal. He has to explain to his superiors the competitive pressures, the negotiation resistance by the other party, the need to change headquarters approach to international business. He is caught between: (a) the headquarters approach of not making any more concessions than necessary, and (b) the foreign firm's expectation of flexibility on the part of his company. And when he goes out again on his next tour of international negotiation, he has to do all of this again. He has to be successful in bringing home deal after deal and very successful deals at that.

\subsection{Negotiator Needs Multiple and Superior Skills}

These negotiation deals may be about joint ventures, cooperative agreements, sales deals, outsourcing deals, managerial and technical cooperation deals, financial deals, or purchasing deals. He must show mastery over all details, anticipate objections and concessions, focus on achieving mutual long term progress and benefits for his firm and the other parties.

Multiple skills and wide experience of the negotiator would be a great asset in the negotiation process. Good negotiators are usually more experience and more matured.

\section{Effective Negotiation Strategies: The Negotiator Has to Do it Al}

Negotiation is very culture bound, as Wa (2015) explains that negotiation process and approaches has to be modified to a particular culture; different cultures need different approaches and strategies, as in the case of the differences in the preferred negotiation practices in culturally different China and India. What may work well in one culture may not work well in another culture. Each negotiator must first screen his proposed approach for the applicability to the local culture, customs, protocol and the negotiation situation. Here are some generalized recommendations that are probably useful for effective negotiations in many cross-cultural settings, although care still should be taken to see if any of these suggestions, however broad and general, are out of tune with the local setting and culture.

\subsection{Continuous and Mutually Beneficial Inter-Organizational Relationship}

The emphasis should be on long term, continuous mutually beneficial business relationships, not immediacy and not a one-time deal. With this in mind the approach should be to arrive at a deal by which both parties significantly benefit. Neither party should feel that it came off a big winner at a great cost to the other.

Negotiation should be viewed as a mutual alignment process conducted in a cooperative, helpful and friendly spirit. In essence, first achieving a common ground and mutual understanding becomes the base for launching future progress of detailed aspects of negotiations.

\subsection{Keeping Negotiations Cordial, Friendly and Pleasant: Always Keeping Good Relationships}

Although the final outcome of the negotiation is a signed contract or agreement, the real thing should be the beginning of a long, friendly, mutually beneficial inter-organizational relationship. The contract is a legally enforceable agreement and, therefore, many cultures are comfortable. However, in some cultures, the agreement is arrived at by a handshake. In either case, the goal should be to set up a window of relationship opportunities. Mutual trust and cooperative spirit are the effective ways of starting a long term relationship of mutual benefit. Frankness and clear identification of important issues (of agreement and disagreement) focus on what would help the other achieve its goals.

Building good relationships means spending time in social, cultural and natural settings, e.g., formal dinners, performing social graces, visiting company locations, and important national and city sites. These activities may appear to be less directly related to the business of negotiation at hand. However, it is through these social graces that each party can feel the other party and develop a first-hand sense of trust and interpersonal competence, all of which are vital to long term relationships.

\subsection{Computer Based Negotiations}

In the emerging modern computer based, modelling applications to negotiations with unknown opponents, Chen and Weiss (2015) suggest that a more programmed approach. They argue that negotiations that take place within a network of "computational autonomous agents" have become extant and ever increasing. They attribute the growing e-commerce or e-business activities. This reality indicates that a high amount of "automated bilateral 
multi-issue negotiation in complex environments" take place through such algorithms and techniques that make the negotiation processes more rapid and efficient

\subsection{Thorough Preparation is a Must}

Cultural differences among the negotiating parties make it imperative for more advanced preparation. Many successful executives spend one day's prior preparation for every hour's negotiation. This advance preparation is used to develop a clear understanding of issues and problems of the other party, and, the cultural aspects of negotiations and communications. Self-analysis, or analysis of assumptions that the negotiator himself has, and, comparing them with those of the other party, becomes an important topic for advance preparation for international negotiation. This is particularly important to remember when the two parties hail from widely dissimilar cultures (Ribbink and Grimm, 2014).

Since most negotiation situations involve economic implications, it is important for the negotiator to understand all possible scenarios of concession requests by which he might be confronted in the actual negotiation. This means that he must know all economic and financial details for all phases of the transaction. This would make him better prepared for many possible situations without having to guess one's way through.

\subsection{Emphasize the Mutual Interests, Common Needs and Goals}

After a comfortable, initial trust and confidence has been established in the relationship between the two parties, the negotiation moves to the next phase: understanding the specific positions of the parties, and, the underlying reasons of these positions. Both parties must make a conscious effort to understand the other party's position and the supporting reasons for their positions.

He must use his bargaining power judiciously and with restraint, focusing on building relationship and regard of the other party. Using his organizational strength and knowledge to help the other party and solve his problems, facilitate his interests are better approaches than throwing his organizational weight around.

For example, if a company has a rigid policy of uniform fixed global pricing for new equipment lines and if your client in the Middle East is about to place a very big, long term contract, and, in the last phase of negotiations asks for a price discount, you as a negotiator are in a quandary as to what you should do. Your checking with the headquarters is not going to change anything. But you are inventive enough to suggest favorable pricing for the additional equipment and services which the customers want. In this way, both parties win out. This turns a difficult and delicate "win-lose" situation in the last, yet critical phase of negotiations into a "win-win" situation. It also was achieved without any violation of the company's global uniform pricing of its new lines of products.

The negotiator had correctly identified the reason (or emotion in this case) behind the customer's position to be that he wanted to feel that because he was giving a significantly big, long term deal, he should get a discount to symbolize the seller's appreciation of receiving the big order. The negotiator in this case skillfully handled the situation by analyzing the reasoning behind the position, and acted with creativity. When considering contextual factors, Ribbink and Grimm (2014) explain in their empirical study of interactions in global supply chains the impact of low and high context cultures on the nature of negotiations. They found that greater cultural distances between two players adversely affect joint profits, mutual trust and bargaining strategy; on the other hand, when the two players in the same or similar culture(s) would experience a more favorable negotiation situation and outcomes.

\subsection{Be Open Minded About Other Cultures}

Do not stereotype cultures, e.g., the English are cold, the Italians are emotional, the Americans are not deep or loyal in relationships, and the French are too patriotic. Thus, you may find a particular English person warm, an Italian very rational, an American clearly a loyal friend, a Middle Easterner to the point in discussions and a Japanese person's very expressive in timely responses.

When we keep an open mind and do not generalize or label an entire national or regional culture, then we can make better progress in our negotiations. That is because we have expunged these stereotypes from our minds and the other party would see all this in us. He would see us as fair, balanced and very reasonable. This would make us effective because the other party is willing to trust us even more, thereby creating a more conducive climate for a mutually cooperative, friendly, helpful and understanding relationship. All this was possible because you had a clear heart as you saw him through unprejudiced eyes. And he felt most comfortable about this because he intuitively sensed this in you.

Khakar and Rammal (2012), in their empirical study in Arab cultures, found the styles that Arab managers used in dealing with their counterparts from other parts of the world. . In their research they found that the business connections, social networks and referent power bases (or, "wasta") are used to secure new businesses. They also 
observed that the regional political instability offered fertile opportunities to scholars for such on-going research. The Arab world is often the object of much attention for research because of the important economic region due to its natural resources, geographic location and political influence. Scholars and business people from around the world have often not paid enough attention to doing proper research for understanding the realities of the Arab style of interactions and negotiations as they do business with foreigners. Their study, involving semi-structured interviews, addressed this deficiency by investigating the characteristics of important socio-economic, cultural and political factors. Similarly, Wa (2015) provides effective approaches for negotiating in India and China.

\subsection{First, Understand the Other Party Better (in the other party's terms)}

Before taking a plunge, take stock of the negotiation situation. Before embarking on a talking spree, listen carefully and fully. Good negotiators precisely understand the specific needs of the other parties through intense and active listening. Then they do their best to address specific concerns, needs and expectations. In this way negotiation is successful because the two sides were good listeners, and they understood each other well. The negotiator did not plunge into the making of his propositions without knowing the other's frame of reference and needs. Peleckis (2014) clearly explains this negation-related communication issue:

"Negotiating communication has created new challenges, as business becomes global, and the distance between the two parties does not allow to negotiate fully - to take full advantage of the bargaining power remotely. The use of innovation can be beneficial not only to support the negotiation process but also in the preparation phase of the negotiations. In order to properly prepare for negotiations is need to form an effective negotiating team whose analytical work and skills could help to achieve the highest outcome of the negotiations. This is particularly important in the preparation and in the course of intercultural negotiations, which require an understanding of other cultures, other languages, possession of legal knowledge, knowledge of the negotiation context, etc. In preparation for the negotiation phase is needed to know the best way possible about the other side of the negotiation. Knowing the technical communication capabilities of other negotiation side it is possible to prepare effective negotiation support tools. Negotiation's success often depends on the effectiveness of the preparation - the better it will be known the other side of the negotiation and negotiation context, the better results will be achieved. In this article is made the analysis of global scientific literature in international business negotiations innovations. As well there is examined the preparation of business negotiations and considered the formation of negotiating teams. In the conclusions the author provides suggestions for further negotiations research."

\subsection{Pace of Negotiations}

Sense the other party's preferred pace of negotiations. If he wants to go slowly and systematically, then do not rush him. He wants to know more details in the earlier phases of the negotiations so that he feels minimally comfortable about this while negotiation process.

In different phases the other party may not be interested in too much depth. In that case the negotiator should skip the depth, and only provide the salient features. The pace of negotiations could vary very much, at sometimes making rapid and desirable progress, and at some other times, they can get bogged down into standstill intransigence. Yet, he has to be patient, equanimous, and always well collected and well composed.

\subsection{Timing is Everything}

Sense the correct timing. A good negotiator knows when to suggest a delicate or difficult proposition or ask a delicate question. The focus should be on knowing when to introduce a particular topic.

He should create a comfortable, trusting atmosphere by giving proper details and assurance about concerns. He must introduce the effective solutions at the correct time. He has a continuous exposure of different issues that he has to embrace. He has to sequence these issues and select them in a proper sequence.

\subsection{Understand the Needs and Be Flexible}

By keeping one's views of the negotiation situation open, the negotiator can be more open to different ways of reaching a more beneficial solution or agreement. Despite thorough preparation and sound analyses, many activities during the negotiation process can go astray.

The negotiator must remain flexible, open and unperturbed by departures from a planned method. For example, schedule of travel, meetings, site visits, and specific phases of discussions can and do change. These result in the negotiator taking a positive approach and not being ruffled by these disruptions in his process of accomplishing the deal. Also, the other party may change the format for discussions, may not have prepared some needed analyses or details from his side, or may choose a relaxation trip instead of discussion on details. The negotiator must take these in his stride. 


\section{Conclusions}

Negotiators need preparation, understanding, a friendly or mutually "win-win" helpful approach, develop insights about the underlying reasons of the other party's positions and views, be open-minded and do not generalize or stereotype cultures, be flexible and positive, and develop a sense of timing for introducing issues and of pace (at which to progress) that is comfortable to the other party.

As much of business transactions move in international arenas, negotiations will require more skills to understand how other cultures negotiate. This would place additional challenges on the negotiator from one culture. His cultural awareness of other peoples of other cultures would help his in negotiations process. His knowledge and sensitivity, and, behavioral flexibility would serve him well.

Effective negotiation requires being aware and sensitive of and responsive to the nature of the negotiation situation, and, the other party's needs, expectations and feelings. Such sensitivity usually brings greater congeniality and pleasant atmosphere to the negotiations situation.

He must use his organizational bargaining power sparingly, and, instead he should focus on empathy and building positive relationship with the other party. He should focus on achieving a mutually satisfactory and happy agreement where both sides are equally and equitably content with the quality and content of the agreement. He should use his insights and technical and organizational knowledge to solve the other party's problems and further his interests.

For the negotiations process to be successful, the often tension ridden nature of the negotiations process requires a negotiator to be skillfully blending of the correct negotiation strategy, the making of proper appeals to the other party, the projecting of the correct personal image of one's self, the bringing to the table of the correct negotiation topics in the correct sequence, and the timely offering of helpful and facilitating solutions to the negotiations problems and issues.

While the short term goal is the arriving of a formal and legal agreement, the long term goal should be the continuous development of a mutually happy relationship that progresses the interests of both parties. The successful negotiator is well trusted, well respected, culturally sensitive and behaviorally flexible, fluent and effective communicator with emphasis on building empathy, and is always happily welcomed by the other parties whenever he communicates with them.

\section{References}

Chen, S., \& Gerhard, W. (2015). An approach to complex agent-based negotiations via effectively modelling unknown opponents. Expert Systems With Applications, 42(5), 2287-2304.

Fells, R., Helen, R., Peter, P., \& Ursula, F. O. (2015). Unraveling Business Negotiations Using Practitioner Data. Negotiation and Conflict Management Research, 8(2), 119-136.

Khakhar, P., \& Hussain, G. R. (2012). Culture and business networks: International business negotiations with Arab managers. International Business Review, 12, 23-55.

Moran, R. T., \& William, G. S. (1991). Dynamics of successful international business negotiations. Houston: Gulf Publishing.

Peleckis, K. (2014). International business negotiations: Innovation, negotiation team, preparation, Procedia Social and Behavioral Sciences, 110, 64-73.

Ribbink, D., \& Curtis, M. G. (2014). The impact of cultural differences on buyer-supplier negotiations: An empirical study. Journal of Operations Management, 32(3), 114-126.

Wa, Y. (2015). Understanding "the elephants in the room": The roadmap to prepare for business negotiations in India and China. Journal of International Business and Law, 67, 23-35.

\section{(cc) BY}

This work is licensed under a Creative Commons Attribution 3.0 License. 